\title{
FREQUENCY OF RETINOPATHY IN LOW BIRTH WEIGHT INFANT AT TERTIARY CARE HOSPITAL.
}

1. MBBS, MCPS, FCPS Associate Professor of Ophthalmology Quaid-e-Azam Medical College/ Bahawal Victoria Hospital Bahawalpur.

2. MBBS, DCH, FCPS

Senior Registrar of Pediatrics Quaid-e-Azam Medical College/ Bahawal Victoria Hospital Bahawalpur.

3. MBBS, DOMS, FCPS, FRCS Professor of Ophthalmology Quaid-e-Azam Medical College/ Bahawal Victoria Hospital Bahawalpur.

Correspondence Address: Dr. Muhammad Younis Tahir Department of Ophthalmology Quaid-e-Azam Medical College/ Bahawal Victoria Hospital Bahawalpur. doctoryounis@gmail.com

Article received on: 01/08/2019

Accepted for publication: $15 / 11 / 2019$

\section{Muhammad Younis Tahir ${ }^{1}$, Iftikhar Ahmad ${ }^{2}$, Soufia Farrukh ${ }^{3}$}

ABSTRACT... Objectives: To find out the frequency of retinopathy in low birth weight infant presenting at tertiary care hospital, Bahawalpur. Study Design: Cross sectional study. Setting: Department of Ophthalmology, Bahawal Victoria Hospital, Bahawalpur. Period: July 2018 to December 2018. Material \& Methods: Neonatal eye examination was performed for ROP. Results: Total 78 neonates were recruited for present study and ROP was assessed. Mean gestational age of neonates was $32.54 \pm 3.79$ weeks. Mean weight was $1445.51 \pm 517.373$ grams. Out of 78 neonates, ROP was observed in 28 (36\%) neonates. ROP was found in 27 (42.19\%) neonates of premature group and in $1(7.14 \%)$ neonates of at term group. ROP was found in 1 (3.23\%), 5 (29.41\%) and 22 (73.33\%) neonates respectively in weight group $1500-2500 \mathrm{~g}, 1000-1500 \mathrm{~g}$ and $<1000 \mathrm{~g}$ group. Male neonates were $35(44.87 \%)$ and female neonates were $43(55.13 \%)$. Development of ROP was not significantly $(P=0.248)$ associated with gender of the neonates. Statistically significant association between ROP and oxygen supplementation was observed with $p$ value 0.021 . Conclusion: Results showed higher association of development of ROP with gestational age. Oxygen supplementation and oxygen concentration was also associated with development of ROP. Findings also showed no effect of gender and duration of hospital stay on ROP.

Key words: $\quad$ Birth Weight, Oxygen Supplementation, Prematurity, Retinopathy.

Article Citation: Tahir MY, Ahmad I, Farrukh S. Frequency of Retinopathy in low birth weight infant at tertiary care hospital. Professional Med J 2020; 27(2):365-370. DOI: 10.29309/TPMJ/2020.27.2.4001

\section{INTRODUCTION}

In 1942 Terry described a vasoproliferative disorder which occurs in the retina of premature infants known as retinopathy of prematurity (ROP). ${ }^{1}$ There are 1.4 million blind children worldwide (2/3 in developing countries), estimated by WHO. In approximately 50000 children, ROP was the cause of blindness. ${ }^{2}$ To reduce such ROP incidence, proper management is required for very low birth weight (VLBW) infants. ${ }^{3}$ The frequency of ROP in infants has increased due to improved survival rate of infants during the last 10 years. Developed countries have significantly less ROP cases than developing countries. ${ }^{4}$

High premature births, lack of awareness and skilled people or financial constraints with the lack of screening and treatment in most neonatal units are causing more ROP incidence. ${ }^{5}$ Majorly gestational age (GA) and birth weight (BW) are the risk factors of ROP. Infants at risk should be examined by ophthalmologist and studies has given effective ROP screening programs in developed countries. ${ }^{6}$ It was thought, the contributory factors for developing ROP were immaturity and higher levels of oxygen. ${ }^{7}$ But even after long duration of oxygen with Supplementation of oxygen, not all infants developed ROP. Factors like male sex, maternal hypertension, respiratory distress syndrome, apnea, sepsis, genetic factors, multiple births, blood transfusions and intraventricular hemorrhage are involved in ROP. ${ }^{8}$

\section{MATERIAL AND METHODS}

This cross sectional study was conducted at Department of Ophthalmology, Bahawal Victoria Hospital, Bahawalpur from July 2018 to December 2018.

In this study total 78 neonates of both gender having weight $800-2500$ gram, having gestational age 28-40 weeks were selected. Patients with 
congenital cataract, patients with congenial malformation, patients with chromosomal anomalies and patients with tumor of eyes were excluded from the study.

Digital weighing machine was used for weight. Estimation of gestational age was done by maternal history and by abdomen ultrasound.

All the selected patients were examined for ROP. Before eye examination, pupils were dilated by instilling topical $0.5 \%$ cyclopentolate and $0.5 \%$ phenylephrine eye drops 3 times (one minute apart). Indirect ophthalmoscopy was performed using a binocular indirect ophthalmoscope. Lid speculum and scleral depressors were used routinely. The diagnosis of ROP was made based on the amount of abnormal blood vessel development. Findings were noted on predesigned proforma in term of ROP Yes/No.

SPSS version was used to analyzed the data. Continuous variables was presented as mean and SD and categorical variables were presented as frequency and percentage. Chi-square test used to assess the association of ROP with different variables. $P$-value $\leq 0.05$ was considered statistically significant.

\section{RESULTS}

Total 78 neonates were recruited for present study and ROP was assessed. Out of 78 neonates, ROP was observed in 28 (36\%) neonates. (Figure-1)

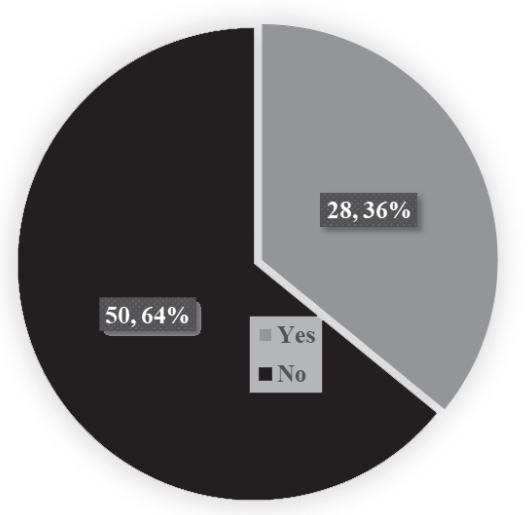

Figure-1. Frequency of ROP

Mean gestational age of neonates was 32.54 \pm 3.79 weeks. Selected neonates were divided into premature group and at term group. Total 64 (82.05\%) neonates belonged to premature group and $14(17.95 \%)$ neonates belonged to at term group. ROP was found in 27 (42.19\%) neonates of premature group and in $1(7.14 \%)$ neonate of at term group. Significantly $(P=0.013)$ higher rate of ROP was observed in premature group as compared to at term group. (Table-I).

Mean weight was $1445.51 \pm 517.373$ grams. Neonates were divided into three weight categories i.e. $1500-2500 \mathrm{~g}, 1000-1500 \mathrm{~g}$ and $<1000 \mathrm{~g}$. Total 31 (39.74\%) neonates were between 1500-2500 g, 17 (21.79\%) neonates were between 1000$1500 \mathrm{~g}$ and 30 (38.46\%) neonates were <1000 g. ROP was found in 1 (3.23\%), 5 (29.41\%) and 22 (73.33\%) neonates respectively in weight group $1500-2500 \mathrm{~g}, 1000-1500 \mathrm{~g}$ and $<1000 \mathrm{~g}$ group. Development of ROP was significantly $(P=0.000)$ associated with weight of the neonates. (Table-II).

Male neonates were 35 (44.87\%) and female neonates were 43 (55.13\%). ROP was found in $15(42.86 \%)$ male neonates and in 13 (30.23\%) female neonates. Development of ROP was not significantly $(P=0.248)$ associated with gender of the neonates. (Table-III).

Mean duration of oxygen supplementation was $10.29 \pm 5.822$ hours. In 33 (42.31) neonates, duration of oxygen supplementation was $<12$ hours and in 45 (57.69) neonates was $\geq 12$ hours. ROP was develop in 7 (21.21) neonates of $<12$ hours group and in 21 (46.67) neonates of $\geq 12$ hours group. (Table-IV).

Selected neonates were divided into two groups according to Oxygen concentration i.e. $\leq 60 \%$ group and $>60 \%$ group. Out of 21 (26.92\%) neonates of $\leq 60 \%$ group, ROP was found in 9 (42.86\%) neonates. Total 57 (73.08\%) neonates belonged to $>60 \%$ group, ROP was observed in 19 (33.33\%) neonates. Statistically insignificant association between oxygen concentration and development of ROP was noted with $p$ value 0.437. (Table-V).

Duration of hospital stay of $52(66.67 \%)$ neonates and 26 (33.33\%) neonates were between 1-15 
days and 16-30 days respectively. ROP was noted in 14 (26.92) neonates and 14 (53.85\%) neonates respectively in 1-15 days group and 16-30 days group. Statistically insignificant association between ROP and duration of hospital stay was noted with $p$ value 0.384. (Table-VI).

\begin{tabular}{|c|c|c|c|c|}
\hline \multirow{2}{*}{ Gestation } & \multicolumn{2}{|c|}{ ROP } & \multirow{2}{*}{ Total } & \multirow{2}{*}{ P-Value } \\
\hline & Yes (\%) & No (\%) & & \\
\hline Premature & $27(42.19)$ & $37(57.81)$ & $64(82.05)$ & \multirow{3}{*}{0.013} \\
\hline Term & $1(7.14)$ & $13(92.86)$ & 14 (17.95) & \\
\hline Total & $28(36)$ & $50(64)$ & 78 & \\
\hline
\end{tabular}

\begin{tabular}{|l|c|c|c|c|}
\hline \multirow{2}{*}{$\begin{array}{c}\text { Oxygen } \\
\text { Concentration }\end{array}$} & Yes (\%) & No (\%) & Total & P-Value \\
\hline $1500-2500$ & $1(3.23 \%)$ & 30 & $31(39.74)$ & \\
\hline $1000-1500$ & $5(29.41 \%)$ & 12 & $17(21.79)$ & \multirow{2}{*}{0.000} \\
\hline$<1000$ & $22(73.33 \%)$ & 8 & $30(38.46)$ & 78 \\
\hline Total & $28(36)$ & $50(64)$ & \\
\hline
\end{tabular}

\begin{tabular}{|l|c|c|c|c|}
\hline \multirow{2}{*}{ Gender } & \multicolumn{2}{|c|}{ ROP } & Total (\%) & \multirow{2}{*}{ P-Value } \\
\cline { 1 - 4 } & Yes (\%) & No (\%) & $35(44.87)$ & \multirow{2}{*}{0.248} \\
\hline Male & $15(42.86)$ & $20(57.14)$ & $43(55.13)$ & 78 \\
\hline Tomale & $13(30.23)$ & $30(69.77)$ & $50(64)$ & \\
\hline & $28(36)$ & Table-III. Association of ROP with gender. & \\
\hline
\end{tabular}

\begin{tabular}{|l|c|c|c|c|}
\hline \multirow{2}{*}{$\begin{array}{c}\text { Oxygen Supplementation } \\
\text { (Hours) }\end{array}$} & \multicolumn{2}{|c|}{ ROP } & Total (\%) & P-Value \\
\hline$<12$ & $7(21.21)$ & $26(78.79)$ & $33(42.31)$ & \multirow{2}{*}{0.021} \\
\hline$\geq 12$ & $21(46.67)$ & $24(53.33)$ & $45(57.69)$ & \\
\hline Total & $28(36)$ & $50(64)$ & 78 & \\
\cline { 1 - 4 } & \multicolumn{2}{r|}{ Table-IV. Association of ROP with Duration of oxygen supplementation. } \\
\end{tabular}

\begin{tabular}{|c|c|c|c|c|}
\hline \multirow{2}{*}{$\begin{array}{c}\text { Oxygen } \\
\text { Concentration }\end{array}$} & Yes (\%) & No (\%) & Total (\%) & \multirow{2}{*}{ P-Value } \\
\hline$\leq 60 \%$ & $9(42.86)$ & $12(57.14)$ & $21(26.92)$ & \multirow{2}{*}{0.437} \\
\hline$>60 \%$ & $19(33.33)$ & $38(66.67)$ & $57(73.08)$ & \\
\hline Total & $28(36)$ & $50(64)$ & 78 & \\
\hline & Table-V. Association of ROP with oxygen concentration. \\
\hline
\end{tabular}

\begin{tabular}{|c|c|c|c|c|}
\hline \multirow{2}{*}{$\begin{array}{c}\text { Duration of Hospital } \\
\text { Stay (Hours) }\end{array}$} & Yes (\%) & No (\%) & Total (\%) & P-Value \\
\hline $1-15$ & $14(26.92)$ & $38(73.08)$ & $52(66.67)$ & \multirow{2}{*}{ ROP } \\
\hline $16-30$ & $14(53.85 \%)$ & $12(46.15 \%)$ & $26(33.33)$ & 78 \\
\hline Total & $28(36)$ & $50(64)$ & 78 \\
& Table-VI. Association of ROP with duration of hospital stay. & \\
\hline
\end{tabular}




\section{DISCUSSION}

ROP is one of the most fatal complications developed in neonates. Embryonic retinal arteries grow from the end of $1^{\text {st }}$ trimester till birth. Visual disorders are led by fragile vessels which occurs due to inhibited or unusual growth of eye. ${ }^{9}$ Even after availability of progressed treatment, ROP is still extensively becoming the cause for visual disorders in developed countries. ${ }^{10}$ Late diagnosis of disease can cause blindness but it can be prevented by timely recognition of disease. ${ }^{11}$ It can develop during the $32^{\text {nd }}$ week of gestation (preterm delivery) and also due to birth weight being $<1500$ g.

ROP risk factors includes heart disease, infection, apnea, respiratory disorders, intraventricular hemorrhage, decreased $\mathrm{PH}$, bradycardia, decreased blood O2, vitamin $E$ deficiency, transfusion, increased oxygen $\left(\mathrm{O}_{2}\right)$ consumption, increased blood carbon dioxide, duration of ventilation, amount of received oxygen and various maternal factors (preeclampsia, diabetes, mother's smoking). ${ }^{12,13}$

The purpose of present study was to evaluate the frequency of ROP in neonates admitted in Paediatric wards of Bahawal Victoria Hospital, Bahawalpur.

Total 78 neonates were recruited for present study and ROP was assessed. Out of 78 neonates, ROP was observed in 28 (36\%) neonates, mean gestational age of neonates was $32.54 \pm 3.79$ weeks and Mean weight was $1445.51 \pm 517.373$ grams.

In a study by Adio et $\mathrm{al}^{14}$, mean gestational and mean birth weight of neonates was $28.98 \pm$ 1.38 weeks and $1411 \pm 128$ gram. In this study over all prevalence of ROP was $47.2 \%$ which is higher than our findings. In USA and Europe, ROP incidence is between $10-34 \% .{ }^{15}$ In one study conducted in China, frequency of ROP was $26 \%$ which is comparable with our study. ${ }^{16}$

In another study by Shah et $\mathrm{al}^{17}$, reported frequency of ROP was $29.2 \%$ which is also comparable with our study. Taqui et $\mathrm{al}^{18}$ reported frequency of ROP in $32.4 \%$ neonates. Neonates were divided into three weight categories i.e. $1500-2500 \mathrm{~g}, 1000-1500 \mathrm{~g}$ and $<1000 \mathrm{~g}$. total $31(39.74 \%)$ neonates were between 1500-2500 g, 17 (21.79\%) neonates were between 1000$1500 \mathrm{~g}$ and 30 (38.46\%) neonates were <1000 g. ROP was found in 1 (3.23\%), 5 (29.41\%) and 22 (73.33\%) neonates respectively in weight group $1500-2500 \mathrm{~g}, 1000-1500 \mathrm{~g}$ and $<1000 \mathrm{~g}$ group. Development of ROP was significantly ( $P$ $=0.000)$ associated with weight of the neonates.

Selected neonates were divided into premature group and at term group. Total 64 (82.05\%) neonates belonged to premature group and 14 (17.95\%) neonates belonged to at term group. ROP was found in 27 (42.19\%) neonates of premature group and in $1(7.14 \%)$ neonates of at term group. Significantly $(P=0.013)$ higher rate of ROP was observed in premature group as compared to at term group.

Lermann et $\mathrm{al}^{19}$, also reported comparable (27.2\%) results in their study. Retinopathy of prematurity was confirmed in $50 \%$ of the patients with weights below $1,000 \mathrm{~g}$ and $71.5 \%$ of newborn infants born at gestational ages of less than 28 weeks. Reisner et $\mathrm{al}^{20}$ examined 1070 newborns and found $20 \%$ of them with ROP $<2500 \mathrm{~g}, 21 \%$ weighing $<1500 \mathrm{~g}$, $35 \%<1250 \mathrm{~g}$ and $72 \%$ were $<1000$ gram. Reisner et al ${ }^{20}$ studied 1,070 newborn infants, observing a $20 \%$ prevalence of ROP among newborn infants weighing less than $2,500 \mathrm{~g}, 21 \%$ for those below $1,500 \mathrm{~g}, 35 \%$ for weights under $1,250 \mathrm{~g}$ and $72 \%$ for babies born weighing less than 1,000 g. Threshold disease was found in $9 \%$ of the newborn infants with weights below 1,500 g.

Charles et al found ROP in $72 \%$ neonates having weight $<1200 \mathrm{~g}$ and $66 \%$ newborn having gestational age $<32$ weeks. ${ }^{21}$ Purohit et al examined 3025 newborn for ROP and found ROP in $11 \%$ newborn having weight $<1750 \mathrm{~g}$ and in $43 \%$ having birth weight $<750 \mathrm{~g} .{ }^{22}$ Hussain et al ${ }^{23}$ and Larsson et $\mathrm{al}^{24}$ reported frequency of ROP as $21.3 \%$ and $25.5 \%$ respectively.

\section{CONCLUSION}

Results showed development of ROP with 
gestational age was highly significant. Oxygen supplementation and oxygen concentration was also associated with ROP. Findings also showed no effect of gender and duration of hospital stay on ROP. Copyright@ 15 Nov, 2019.

\section{REFERENCES}

1. Terry TL. Extreme prematurity and fibroblastic overgrowth of persistent vascular sheath behind each crystalline lens. I. Preliminary report. Am J Ophthalmol. 1942; 25: 203-4.

2. Dandona R, Dandona L. Childhood blindness in India: A population based perspective. $\mathrm{Br} \mathrm{J}$ Ophthalmol. 2003 Mar; 87(3):263-5.

3. Hwang JH, Lee EH, Kim EA-R. Retinopathy of prematurity among very-low-birth-weight Infants in Korea: Incidence, Treatment, and Risk Factors. J Korean Med Sci. 2015 Oct; 30(Suppl 1):S88-94.

4. Dogra MR, Katoch D. Clinical features and characteristics of retinopathy of prematurity in developing countries. Ann Eye Sci 2018;3:4. Doi: 10.21037/aes.2017.12.08

5 Sohaila A, Tikmani SS, Khan IA, Atiq H, Akhtar ASM, Kumar $P$, et al. Frequency of retinopathy of prematurity in premature neonates with a birth weight below 1500 grams and a gestational age less than 32 weeks: A Study from a Tertiary Care Hospital in a Lower-Middle Income Country.... PLoS One [Internet]. 2014 Jul 2 [cited $2019 \mathrm{Jul}$ 18]; 9(7). Available from: https://www. ncbi.nlm.nih.gov/pmc/articles/PMC4079563/

6. Fierson WM. Screening examination of premature infants for retinopathy of prematurity. Pediatrics. 2013 Jan; 131(1):189-95.

7. Retinopathy of prematurity [Internet]. [Cited 2019 Jul 18]. Available from: https://www.ncbi.nlm.nih.gov/ pmc/articles/PMC4020289/

8. Slidsborg C, Jensen A, Forman JL, et al. Neonatal risk factors for treatment-demanding retinopathy of prematurity: A Danish national study. Ophthalmology. 2016; 123:796-803. 8.
9. Zin A, Gole GA. Retinopathy of prematurity-incidence today. Clinics in perinatology. 2013 Jun 1; 40(2):185200.

10. Gergely K, Gerinec A. Retinopathy of prematurity-epidemics, incidence, prevalence, blindness. Bratislavske lekarske listy. 2010; 111(9):514-7.

11. Wilson CM, Ells AL, Fielder AR. The challenge of screening for retinopathy of prematurity. Clinics in perinatology. 2013 Jun 1; 40(2):241-59.

12. Senthil MP, Salowi MA, Bujang MA, Kueh A, Siew $\mathrm{CM}$, Sumugam K, Gaik CL, Kah TA. Risk factors and prediction models for retinopathy of prematurity. The Malaysian journal of medical sciences: MJMS. 2015 Sep; 22(5):57.

13. GEBEŞÇE A, USLU H, KELEŞ E, Yildirim A, GÜRLER $B$, Yazgan H, BAŞTÜRK B, DEMIRDÖVEN M, Tonbul A. Retinopathy of prematurity: incidence, risk factors, and evaluation of screening criteria. Turkish journal of medical sciences. 2016 Feb 17; 46(2):315-20.

14. Adio AO, Ugwu RO, Nwokocha CG, Eneh AU. Retinopathy of prematurity in Port Harcourt, Nigeria. ISRN ophthalmology. 2014 Feb 4; 2014.

15. Karkhaneh R, Mousavi SZ, Riaziesfahani $M$, et al. Incidence and risk factors of retinopathy of prematurity in a tertiary eye hospital in Tehran. $\mathrm{Br} J$ Ophthalmol. 2008; 92: 1446-1449.

16. Wu T, Zhang L, Tong Y, Qu Y, Xia B, Mu D. Retinopathy of prematurity among very low-birth-weight infants in china: Incidence and perinatal risk factors. Invest Ophthalmol Vis Sci. 2018 Feb 1; 59(2):757-63.

17. Shah VA, Yeo $C L$, Ling $Y L$, Ho LY. Incidence, risk factors of retinopathy of prematurity among very low birth weight infants in Singapore. Ann Acad Med Singapore. 2005; 34: 169-178.

18. Taqui AM, Syed R, Chaudhry TA, Ahmad K, Salat MS. Retinopathy of prematurity: Frequency and risk factors in a tertiary care hospital in Karachi, Pakistan. Journal of the Pakistan Medical Association. 2008; 58(4):186. 
19. Lermann VL, Fortes Filho JB, Procianoy RS. The prevalence of retinopathy of prematurity in very low birth weight newborn infants. Jornal de pediatria. 2006; 82(1):27-32.

20. Reisner SH, Amir J, Shohat M, Krikler R, Nissenkorn I, Ben- Sira I. Retinopathy of prematurity: Incidence and treatment. Arch Dis Child. 1985; 60:698-701.

21. Charles JB, Ganthier RJ, Appiah AP. Incidence and characteristics of the retinopathy of prematurity in a low-income inner-city population. Ophthalmology. 1991; 98:14-7.
22. Purohit DM, Ellison RC, Zierler S, Miettinen OS, Nadas AS. Risk factors for retrolental fibroplasia: Experience with 3,025 premature infants. Pediatrics. 1985; 76:339-44.

23. Hussain N, Clive J, Bhandari V. Current incidence of retinopathy of prematurity, 1989-1997. Pediatrics. 1999; 104:e26.

24. Larsson E, Holmtröm G. Screening for retinopathy of prematurity: Evaluation and modification of guidelines. Br J Ophthalmol. 2002; 12:506-11.

\begin{tabular}{|c|c|c|c|}
\hline \multicolumn{4}{|c|}{ AUTHORSHIP AND CONTRIBUTION DECLARATION } \\
\hline Sr. \# & Author(s) Full Name & Contribution to the paper & Author(s) Signature \\
\hline 1 & Muhammad Younis Tahir & & $\Leftrightarrow$ \\
\hline 2 & Iftikhar Ahmad & Data collection. & HAimstor \\
\hline 3 & Soufia Farrukh & Data analysis and editing. & \\
\hline
\end{tabular}

